\title{
RESEÑAS
}




\section{LA EMIGRACION DE PROFESIONALES Y TECNICOS COLOMBIANOS}

Un caso de transferencia inversa de tecnología. Bogotá: 198047 h.

Este estudio fue realizado para la División de Tecnología de UNCTAD y en él se ana]izan algunos aspectos relacionados con esta problemática. El trabajo se divide en cuatro partes que comprenden los siguientes temas:

El capítulo primero analiza suscintamente las principales corrientes emigratorias internacionales de población colombiana en sus antecedentes, direcciones de la migración, características de los migrantes en términos de sus perfiles demográficos y ocupacionales. En forma específica se analizan la emigración de profesionales y técnicos colombianos destacando los principales países de destino como son Estados Unidos y Venezuela y se suministra información sobre los volúmenes de emigración y las características de los migrantes. Igualmente se estudian algunas de las causas que generan la emigración.

El capítulo segundo se intenta cuantificar las pérdidas económicas en que el país ha tenido como consecuencia de la emigración de sus profesionales y técnicos. Los costos de este éxodo intelectual solo se refieren a los costos directos de educación y no toma en cuanta otro tipo de costos como serían los costos indirectos de educación y lo que la economía nacional deja de percibir por concepto de la reproducción económica de los profesionales emigrados. Así mismo, en este capítulo se analizan los efectos sociales que conlleva la emigración de profesionales y técnicos.

En el capítulo tercero del estudio se analizan las políticas colombianas en materia de migración de recursos humanos altamente calificados, destacándose como en el país no ha existido una política orientada a afectar la emigración de profesionales y técnicos sino solo acciones aisladas para propiciar el retorno de los profesionales antes que para evitar la salida de nuevos emigrantes. Al respecto se analiza una acción concreta como fue la promovida por el Decreto 1397 de 1972 que facilita el retorno de profesionales colombianos residentes en el exterior mediante la concesión de ciertas facilidades arancelarías. Este programa tuvo vigencia de un año (agosto 1972 - julio 1973).

Por último, el capítulo cuarto plantea una serie de posibles soluciones para reducir y racionalizar el éxodo intelectual. Las acciones se proponen para desarrollar en el corto, mediano y largo plazo e incluyen propuestas como la realización de estudios sobre requerimientos, desarrollo, distribución y utilización de profesionales; formulación de políticas educativas acordes con la realidad nacional, creación de servicios de empleo para profesionales y apoyo a las entidades que realizan actividades científico-tecnológicas en el país. En el mediano y largo plazo se consideran también una serie de acciones a desarrollar tendientes a mejorar las condiciones ocupacionales de los profesionales para disminuir la potencialidad de la emigración profesional.

Al final el estudio contiene una extensa bibliografía sobre el tema de la emigración de profesionales y técnicos. 